\title{
Information and Expertise Sharing in Inter-Organizational Crisis Management
}

\author{
Benedikt Ley, Thomas Ludwig, Volkmar Pipek, Dave Randall, Christian Reuter \& \\ Torben Wiedenhoefer \\ University of Siegen, Herrengarten 357072 Siegen, Germany \\ (E-mail: christian.reuter@uni-siegen.de)
}

\begin{abstract}
Emergency or crisis management, as is well-attested, is a complex management problem. A variety of agencies need to collaborate and coordinate in real-time and with an urgency that is not always present in other domains. It follows that accurate information of varying kinds (e.g. geographical and weather conditions; available skills and expertises; state-of-play; current dispositions and deployments) needs to be made available in a timely fashion to the organizations and individuals who need it. By definition, this information will come from a number of sources both within and across organizations. Large-scale events in particular necessitate collaboration with other organizations. Of course, plans and processes exist to deal with such events but the number of dynamically changing factors as well as the high number of heterogeneous organizations and the high degree of interdependency involved make it impossible to plan for all contingencies. A degree of ongoing improvisation, which typically occurs by means of a variety of information and expertise sharing practices, therefore becomes necessary. This, however, faces many challenges, such as different organizational cultures, distinct individual and coordinative work practices and discrete information systems. Our work entails an examination of the practices of information and expertise sharing, and the obstacles to it, in inter-organizational crisis management. We conceive of this as a design case study, such that we examine a problem area and its scope; conduct detailed enquiries into practice in that area, and provide design recommendations for implementation and evaluation. First, we will present the results of an empirical study of collaboration practices between organizations and public authorities with security responsibilities such as the police, fire departments, public administration and electricity network operators, mainly in scenarios of medium to large power outages in Germany. Based on these results, we will describe a concept, which was designed, implemented and evaluated as a system prototype, in two iterations. While the first iteration focuses on situation assessment, the second iteration also includes inter-organizational collaboration functionalities. Based on the findings of our evaluations with practitioners, we will discuss how to support collaboration with a particular focus on information and expertise sharing.
\end{abstract}

Key words: Information management, Expertise sharing, Collaboration, Design case study, Inter-organizational crisis management, $\mathrm{CSCW}$

\section{Introduction}

Sharing information and expertise is crucial in coping and recovery work in crisis management. Having the relevant information and expertise on time and with an 
acceptable degree of accuracy is a key task for all stakeholders. As Schraagen et al. (2010) put it, however:

"Current network structures are often characterized by their ad hoc nature. Large $[\ldots]$ coalitions are assembled out of units that may never have worked together before, nor are they likely to see each other again [...]. In the civilian crisis management area, units are assembled from the police, the fire brigades, and the paramedics to deal with unexpected situations that require coordinated effort for a limited time span. However, during the acute phase of a crisis, central controlled coordination cannot be achieved. This is because, in situations of time pressure, monodisciplinary organizations tend to fall back on well-established routines, each doing what it is they are best in doing. Although these ad hoc organizations are ideally characterized by collaborative working, unlimited communication across all levels and a broad sharing of situation information, in reality there are some bottlenecks that need to be overcome to fully realize their potential." (pp. 117-118).

Organizations and public authorities with security responsibilities, such as the police or fire department, therefore put a lot of effort into making crisis management work as calculable and predictable as possible. However, large incidents (e.g. Hurricane Katrina (USA, 2005), thunderstorm Kyrill (Western Europe, 2007), Hurricane Sandy (US East Coast, 2012), European floods (Central Europe, 2013)) are hardly predictable. The number of influential factors (e.g. weather conditions, the number of people affected or the type of emergency), as well as structural dependencies (e.g. electricity, roads and railways or fuel resources), makes it almost impossible to plan all crisis management activities and calculate information demands well in advance. Hence, as Ley et al. (2012) suggest, many incident situations require the satisfying of ongoing situational information needs, spontaneous decision-making and ad hoc coordination between relevant organizations, different infrastructure providers and administrative staff. Due to this, improvisation work is at the same time both necessary and difficult to do. A completely different level of challenge is arguably seen when a crisis occurs that requires emergency response organizations to collaborate. For instance, when dealing with a medium to large power outage in Germany (the scenario we were looking at in our research project "InfoStrom"), each organization sets up its own crisis management team. Even at county level, a crisis committee has to coordinate efforts and also has to deal with the public. In these situations each organization has to leave its own area of organizational responsibility and is forced to operate and interact outside its system of established practices. However, there are established processes and practices of coordination and collaboration which are usually based on laws and regulations that make it difficult to improvise on an inter-organizational level. Additionally, since laws and regulations also restrict the design and information portfolio of 
emergency management systems in response to a pre-planned scenario, these systems cannot provide full support for improvisation work in these situations.

Our work will focus on inter-organizational collaboration in information and expertise sharing practices of stakeholders who are involved in a medium to large power outage in Germany. These are infrastructure suppliers (e.g. electricity network operators (ENO)), public strategic administration (e.g. crisis committee, operations management, county administration), public operative administration (e.g. police, fire department) and the citizens. We are interested in acquiring deeper understanding of the collaboration practices in information and expertise sharing in an inter-organizational crisis management setting, where improvisation plays an important role for coping and recovery work: What makes it necessary to collaborate with others? What factors influence improvised information and expertise retrieval and sharing activities? What communication lines exist and where do communication strategies fail? We also want to answer the question of how ICT support should be designed to be able to adequately support such practices under these or similar circumstances.

This article is structured as follows: after presenting and discussing relevant related work (section 2), we will introduce our research question and the research field for our three-year study (section 3). We will then describe the methodology of our empirical study and will present our findings with a focus on the aspects relevant for information and expertise sharing that we have found in emergency management (section 4). Afterwards, we will describe the concept behind, and implementation of, an inter-organizational situation assessment client and an inter-organizational information repository (section 5). We will finish by presenting the results of the evaluation (section 6) and then come to a conclusion (section 7).

\section{Related work}

Our CSCW-related work stands as an exemplar of the problems entailed in interorganizational crisis management, and of the nature of improvisation work in these situations. It further shows how information and expertise sharing occurs in practice and demonstrates the degree to which geographic information systems can provide potential solutions to problems experienced. In this section we review the related work in these areas and outline the research gap.

The "endeavor to understand the nature and characteristics of cooperative work with the objective of designing adequate computer-based technologies." (Bannon and Schmidt 1989) has always been the aim of CSCW. In "disaster, crisis, catastrophe, and emergency management [which] are sometimes used synonymously and sometimes with slight differences, by scholars and practitioners" (Hiltz et al. 2011) coordination, cooperation and collaboration are essential. Based on an analysis of the responses to the 2001 World Trade Center attack, Mendonça (2007) suggests that some specifics of emergency management can be 
considered as characteristic: Firstly, (a) rarity of incidences limits opportunities for training and learning. (b) Time pressure forces a convergence of planning and execution. (c) Uncertainty is present because the development of an extreme incident is rarely predictable. Furthermore, extreme events have (d) high and broad consequences, wherefore there is a need to manage interdependencies within a wide range of physical and social systems. The (e) complexity of the event arises, which is partly due to the high and broad consequences. Finally, (f) multiple decision-makers and responding organizations may negotiate with each other, while responding to the event. Based on interviews with emergency responders, Chen et al. (2008) describe similar characteristics but highlight the "disruption of infrastructure support" as an important occurrence.

\subsection{Improvisation in crisis management}

Emergency services face an "unlimited variety of incidents that require interpretation, decision and coordination" (Normark and Randall 2005). The described characteristics of such situations (Chen et al. 2008; Mendonça 2007) make it impossible to plan all these activities ahead. Therefore the necessity for improvisation, Latin improvisus (im = not; provisus $=$ foresee), occurs, which can be defined as a "situated performance where thinking and action seem to occur simultaneously and on the spur of the moment" (Ciborra 1996). Cunha et al. (1999) present a list of more than 50 rather similar definitions of improvisation. Authors variously define it as "to be composed while performed" (Perry 1991), as "thinking and doing unfold simultaneously" and "retrospective sensemaking" (Weick 1996). In this article we will refer to the definition of Perry (1991).

Improvisation becomes necessary when planned decision-making does not work as anticipated. It further arises when "both a demand for speed and action, and an unexpected [...] occurrence are perceived" (Pina Cunha et al. 1999). The necessity to judge highly novel problems and to act quickly reduces the possibility of extensive planning: "Decision makers in emergencies must be prepared to improvise" (Mendonça and Wallace 2007). Instead of trying to eradicate it through automation, the need to appreciate flexibility and effectiveness seems to be more realistic. In this case, "improvisation and preparedness go hand in hand" (Mendonça 2007): without improvisation, emergency management loses flexibility and without preparedness, emergency management loses efficiency. In his description of the Mann Gulch fire disaster in 1949, Weick (1993) outlines intergroup dynamics, such as dealing with the collapse of formal structures and role systems, besides the improvisation of individual firefighters. Accordingly improvisation can be treated as an individual phenomenon (independently solving a problem) or as a team phenomenon: "Collective improvisation" occurs in the interaction of at least two agents and manifests in different tasks: "planning or executing action" at "any level" (Moorman and Miner 1998). The dynamics and specifics of emergencies make it extremely 
difficult to find appropriate approaches to articulating information needs amongst all actors (Heath and Luff 1992). A perspicuous example of (collaborative) improvisation is therefore visible when we examine practical information and expertise sharing behavior among emergency services for situation assessment.

\subsection{Information and expertise sharing in situation assessment}

Conceptions of information need (and, indeed, what is meant by information) remain divided along roughly disciplinary lines. Endsley (1995), for instance, distinguishes between situation awareness as a "state of knowledge" and situation assessment as the "process of achieving, acquiring, or maintaining" that knowledge and sees information gathering as a selection process which leads to the construction of a mental model in accordance with individual goals. The terms largely associate with cognitive psychology and emphasize the role of environmental information acquisition and the various cognitive limits that constrain it. Such definitions are evidently quite different from conceptions of the 'situation' and 'situatedness' that are conventionally found in CSCW, and hence need some unpacking. While we do not share the goals- means assumptions behind the notion of situation awareness, the processes entailed in situation assessment are of some interest. We recognize the need to emphasize the external (environmental) information needs that are necessary for accurate and timely decision-making to unfold. Our concern is not with individual cognitive processes or internal models but with the processes by which (for the most part) factual information is acquired, disseminated, and interpreted across groups of people working in the same area. CSCW tends towards a more interpretive approach and emphasizes notions of 'expertise' or 'knowledge' sharing (Ackerman et al. 2013). Information sharing (or knowledge sharing ${ }^{1}$ ) is used for artifact-centered studies and "takes a perspective in which externalization of knowledge in the form of computational or information technology artifacts or repositories play an important role" (Ackerman et al. 2013). Communicationcentered expertise sharing focuses on "self-organized activities of the organization's members and emphasizes the human aspects" (Ackerman et al. 2003) in addition to information storage and retrieval. It is used "when the capability to get the work done $[\ldots]$ is instead based on discussions among knowledgeable actors and less significantly supported by a priori externalizations" (Ackerman et al. 2013). In line with Ackerman et al. (2013) we will use information sharing mainly to describe the externalization of knowledge and expertise sharing as socialization through shared experience (see also the SECI process of knowledge conversion by Nonaka et al. 2000).

\footnotetext{
${ }^{1}$ Ackerman et al. (2013) mention to "not differentiate between knowledge and information" in their overview article about the "CSCW View of Knowledge Management".
} 
Regardless, the need for up-to-date and accurate information in complex crisis scenarios cannot be completely covered by routine processes and predicted information demands (Ley et al. 2012). Moreover, the necessary information is often not available in a centralized manner, but has to be specifically requested from the control center, from discrete relief forces in the network, or from a third party (Ludwig et al. 2013) or even from citizen (Reuter et al. 2012a). Quarantelli (1988) has summarized research findings since 1963 and has identified a range of different challenges for the communication process and information flow in crisis: For communication inside the organization, he suggests that "during a disaster, the number of staff using the communication system will often increase greatly" (Quarantelli 1988), and may exceed the communication systems' capability and result in overload (Hiltz and Turoff 1985). Information flow between organizations is challenging since "formal contacts must often be established with previously unknown officials within organizations with whom there had been no pre-disaster relationships" (Quarantelli 1988); likewise, "in fact the major problem in emergency management is that the team often does not exist formally until the emergency occurs" (Turoff et al. 2010). Other studies suggest that the "serious communication problems [with regard to] both police and fire departments [...] stem less from lack of equipment or resources but primarily from the $[\ldots]$ pre-disaster planning with respect to information flow" (Wenger et al. 1989). Turoff et al. (2004) draw requirements for emergency management systems which include, "establishing and supporting confidence in a decision by supplying the best possible up-to-date information". They therefore call for methods and techniques which act to maximize the free exchange of information: "Crises involve the necessity for many hundreds of individuals from different organizations to be able to exchange information freely, delegate authority and conduct oversight, without the side effect of information overload". They see prospective solutions in terms of "collaborative knowledge bases" such as "system directories with all the data and information that is available at the time [and the possibility] to add metadata, link data and to enable open and flat communication". Harrald (2006) similarly suggests that "the organizational systems that respond to extreme events must be open systems that allow information to be gathered from and transmitted to the public and nongovernmental organizations in addition to standard governmental sources". Rankin et al. (2011) look at the information and communication flow of persons acting in improvised roles and conclude that "making better use of technology for sharing information could be an important option for strengthening the teams' overall support system and information sharing during disturbances". Accordingly, "just as an artist may employ a new tool, new material or new strategies, so too do decision-makers [...] to rebound when established methods fail or when unanticipated circumstances arise. In both cases, training and preparation remain fundamental, but creative thinking, flexibility and the ability to improvise in newly emergent situations are vital" (Kendra and Wachtendorf 2003). How this is 
to be done, of course, is the problem. One solution is to spend more time looking at informal communication channels with a view to making them more effective.

Previous studies, for instance in software development, have discovered a large variety of informal communication and ad hoc coordination mechanisms in play (Doherty et al. 2012). These authors suggest introducing technologies that support the establishment of "less formal communication channels" instead of structured information management systems, a policy which may also be relevant in crisis management. Hobson et al. (2011), for instance, in an empirical study of the information needs of municipal governments argues that the heterogeneous nature of these needs meant that flexibility was identified as the main requirement. They also point out that employees "rely heavily on manual methods for data sharing" (Hobson et al. 2011). A related study on the challenges of sharing and coordinating information during multi-agency disaster response highlights that the "actual level of information sharing across different organizations is often limited, although it is being promoted". A reason is that agencies "are mainly concerned with obtaining information from others, rather than providing others with information at their disposal" (Bharosa et al. 2010).

\subsection{Collaborative geographic information systems}

In emergencies, information is almost always related to specific locations, therefore geographic information systems (GIS) are of relevance for the presentation of information (Turoff et al. 2004). Li and O'Hara (2009) show that, in decision-making by geographically distributed committees, difficulties arise from not having shared visual access to the information being discussed. Paul and Reddy (2010) also consider the visual aspects: their ethnographic study of collaborative information seeking shows that in addition to the ambiguity of information, the different roles and expertise of group members make sensemaking (Weick 1996) more challenging; they propose the visualization of sensemaking trajectories in order to foster awareness among emergency agencies. Kraut et al. (2002) confirm that "collaborative pairs can perform more quickly and accurately when they have a shared view of a common work area".

Other research has identified the need to locate and exchange information, or to quickly resolve ambiguities about location, in emergency services centers. Pettersson et al. (2004), for instance, highlight the relevance of maps, both paper and electronic. In terms of group work, "most spatial decisions using geographical information are done by teams, but existing geospatial information technologies [...] have been designed for use by individuals", according to Cai (2005): his approach extends distributed GIS with collaborative functionalities and proposes a system architecture that integrates web service-based distributed computing paradigms. The related geo-collaborative software architecture for emergency management planning of Schafer et al. (2007) combines java-based collaborative infrastructures with GIS to support awareness and collaboration 
with annotations and selections that can be shared, along with the possibility to lead or follow another user's map or to link geo-referential data to other content. These functionalities are used in the study by Convertino et al. (2011) focusing on knowledge sharing and activity awareness in distributed emergency management planning with a collaborative geospatial prototype. With a series of paper and software prototypes, they show that using collaboration technology can reduce the coordination efforts among spatially distributed teams. Wu et al. (2013) contribute to the "design research on a new collaborative system [CIVIL] for teams doing complex geo-spatial planning tasks" and suggest to "provide both personal (role-specific) and shared (team) maps and support information transfer between them". Guidelines, based on an evaluation of CIVIL (Wu et al. 2013), include (a) integrating map services that people are familiar with, (b) allowing users to add personal comments and drawings that overlay on maps, (c) providing both shared and private maps as well as supporting the transfer of information between them, (d) providing visualization tools to present information and help information analysis, (e) allowing platform-independent, distributed collaboration and (f) developing architectures that allow delegation of non-critical information management tasks to online public services. Another (mobile) collaborative application named MobileMap (Monares et al. 2011) was designed to help firefighters arrive faster to the emergency scene, to exchange digital information during emergency response processes and to reduce the need for radio communication. Web based geo-collaborative tools also have been examined: Chang and Li (2007) integrate collaborative tools such as chat and video to support participant's awareness and their collaboration. Many of these web-based crisis mashups among Ushahidi (Okolloh 2009) are described by Liu and Palen (2010), who focus particularly on "merging the professional GIS culture with the participatory neo-geographic culture to address the mapping challenges which are likely to arise in this increasingly networked world".

\subsection{The state of play}

The demand for constant updating of information and the need to share expertise in a timely fashion in the crisis management arena - given the lack of workable plans - means that improvisation work is typical rather than abnormal. Improvisation, then, is a consequence of the demand for real-time, relevant, information. At the same time, as we will show, improvisation work suffers "from a lack of options for sharing information among the organizations, but also from a lack of awareness of information about the activities of others, and from a lack of collaboration in consolidating and interpreting the information available" (Ley et al. 2012). Similarly Turoff et al. (2004) describes research opportunities in the area of "collaborative knowledge bases". Cunha et al. (1999) identified an "unresolved issue [which] is the need for close relationships between those improvising"; an application field for CSCW. Cai (2005) mentions a potential for 
collaboration in GIS, which have only partly been addressed, e.g. by Convertino et al. (2011) in terms of activity awareness and Wu et al. (2013) regarding geospatial planning tasks.

There is, therefore, an evident need for research which considers actual collaboration practices and the real - not just intended - use of technologies to support them and the impact on collaborative practices on information technology design and use. That is, existing research identifies a number of areas which, in principle, might improve and ameliorate communication channels in emergencyrelated work across organizational boundaries. How this might be done depends on better knowledge of exactly how, what, when and in what format, information is shared as events unfold. Therefore our study focuses on these improvisation practices (Perry 1991) and the nature of the collaboration between those improvising (Pina Cunha et al. 1999) when assessing situations. We show how this follows on from the need for real-time and relevant information and expertise sharing (Ackerman et al. 2013), with the aim of transferring our empirical findings to technology design for such settings. Specifically, we are interested in the design of a collaborative GIS.

\section{Research question, approach and research field}

Our review of relevant literatures demonstrates that there is a common concern with certain issues, including situation assessment; sharing knowledge, information and expertise, and the use of collaborative channels to do so. That they are of concern is, then, a relatively high-level and commonly understood issue. In contrast, how, in practice, these things are managed is quite another issue, and relatively poorly understood. Our objective, therefore, in this paper is to examine how information and expertise sharing practices are conducted in an improvised manner on an interorganizational level and to propose a socio-technical infrastructure to foster information and expertise sharing in inter-organizational crisis management. This, we felt, necessitated a close, 'on the ground' study of these practices. Ideally, of course, such studies should take place in situ. It is, however, known that ethnographic approaches tout court are difficult to conduct in our chosen context for a number of reasons. These include the difficulty of knowing when disaster will strike, of knowing how serious it might be, of avoiding obstructive behavior, and so on. Therefore, understanding local and inter-organizational collaboration requires us to employ satisficing techniques, as reported below. We chose a specific scenario, that of major power outages, because collaboration between crisis response organizations is particularly difficult when dealing with a crisis of this kind and magnitude. First, we set out to gain an understanding of information and expertise sharing practices within this inter-organizational crisis management setting, where improvisation and informal practices play a significant role when handling crisis situations. Secondly, we contribute knowledge of how to support these sharing activities. We therefore aimed at building a socio-technical artifact, 
which was then evaluated, and in turn, gave us the opportunity to extend our first contribution as well. To fulfill these contributions we followed an action research approach, specifically the methodology of the design case study introduced by Wulf et al. (2011). This method begins with an empirical analysis of the given practices. The data collected informs design by showing how improvisation influences information and expertise sharing in this setting. As technology builders, we can draw on a wealth of detail which is not typically available in more theoretical contributions. The design case study approach also, we should point out, draws attention to the long-term appropriation of new technology. Evaluation, however, of an in situ nature is difficult, not to say impossible, in crisis situations for the reasons we mention above. The circumstances of serious crisis response and rescue tasks are such that neither real-world 'on the ground' investigation nor evaluation are a practical proposition. We did, however, evaluate the artifacts in a work context with representative users. We will explain our methodology in the respective sections in detail.

The findings and concepts that will be discussed in the next sections are derived from a study in the years 2010-2013 focusing on collaboration, situation assessment and decision-making practices during coping and recovery work at emergency services. The study was conducted in two regions of North-Rhine Westphalia in Germany. Region A (Siegen-Wittgenstein) is a densely wooded, hilly county, whereas Region B (Rhein-Erft-Kreis) consists of 10 growing communes west of Cologne. In both regions we focused on several persons and organizations that were affected: infrastructure suppliers (e.g. ENO), public strategic administration (e.g. crisis committee, operations management, and county administration), public operative administration (e.g. police and fire department) and the citizens.

\section{Empirical study on information and expertise sharing practices}

\subsection{Methodology}

The basis for our study, as intimated, was a perceived need for some more detailed understanding of information needs in the complex environment of crisis or emergency management. As we have suggested, traditional (sustained observational) ethnographic research is not practicable in this context. Having said that, if one accepts the views expressed by well-known anthropologists such as Clifford Geertz (1973) and Rabinow and Marcus (2008), as well as the views of CSCW researchers such as Randall et al. (2007) it is legitimate to speak of 'ethnography' as a form of analysis rather than as a specific method. Geertz, for instance, explicitly states:

"And it is in understanding what ethnography is, or more exactly what doing ethnography is, that a start can be made toward grasping what anthropological analysis amounts to as a form of knowledge. This, it must immediately be said, is not a matter of methods." 
We therefore characterize our work as ethnographic because, in the circumstances available to us, we adopted methods which gave us as realistic information as possible about information sharing practices in the application field. In fact, we adopted an informal group interview strategy, akin to what are sometimes called 'focus groups'. We conducted five inter-organizational group discussions (Table 1), each lasting about four hours. The goal of the group discussions was to understand the communication practices of interorganizational crisis management in general. Furthermore, we conducted 22 individual interviews (Table 2) with representatives from organizations which normally would be involved in the scenario we envisaged. The scenario itself was developed with participants from the organizations we were working with and consisted in outline of a windstorm with many incidents and energy breakdowns. The purpose of the scenario was to be able to quickly create a common understanding of a crisis situation. The interviews lasted between one and two hours each and were semi-structured, since they followed a guideline. They were separated into three parts. The first part focused on the participants' role, qualification, tasks and work steps under normal conditions. The second part covered the tasks of each participant during the crisis situation and was based on the developed scenario framework and the third part covered the applied information and communication systems and the problems perceived with these tools. Group discussions and interviews were recorded on audio and transcribed for data analysis. After conducting our empirical work, we derived the basic categories of: technology

Table 1. Group discussions.

\begin{tabular}{|c|c|c|c|}
\hline No & County & Topic & Participants \\
\hline W1 & both & $\begin{array}{l}\text { Challenges in collaboration } \\
\text { practices at ENO, Visit of } \\
\text { Control Center }\end{array}$ & $\begin{array}{l}\text { Middle Management, Operation Engineer, High } \\
\text { Voltage Dispatcher, Low Voltage }\end{array}$ \\
\hline W2 & B & $\begin{array}{l}\text { Challenges in collaboration } \\
\text { practice, Visit of Control } \\
\text { Center }\end{array}$ & $\begin{array}{l}\text { Department Head of Regulatory Authority, } \\
\text { Head of Civil Protection, Head of Police } \\
\text { Control Center, Head of Fire Control Center, } \\
\text { District Fire Chief }\end{array}$ \\
\hline W3 & A & $\begin{array}{l}\text { Challenges in practice, } \\
\text { Visit of Control Center }\end{array}$ & $\begin{array}{l}\text { Department Head: Public Safety, Head of Civil } \\
\text { Protection, Head of Police Control Center, Deputy } \\
\text { Head of Control Center District Fire Chief }\end{array}$ \\
\hline W4 & A & $\begin{array}{l}\text { Analysis of User Interactions } \\
\text { and Communication Flows }\end{array}$ & $\begin{array}{l}\text { Head of Police Control Center, Head of Staff } \\
\text { Coordination, Deputy Head of Control } \\
\text { Center, Local Head of Federal Agency of } \\
\text { Technical Relief, Local Head Red Cross }\end{array}$ \\
\hline W5 & B & $\begin{array}{l}\text { Analysis of User Interactions } \\
\text { and Communication Flows }\end{array}$ & $\begin{array}{l}\text { Department Chief of Regulatory Authority, } \\
\text { District Fire Chief, Red Cross: Disaster } \\
\text { Management, Red Cross: Communications, } \\
\text { Members of other aid agencies. }\end{array}$ \\
\hline
\end{tabular}


Table 2. Interviews.

\begin{tabular}{llll}
\hline No & County & Organization & Participants \\
\hline I01 & A & Administration & Department Chief of Regulatory Authority \\
I02 & A & Police & Head of Control Center \\
I03 & A & Police & Head of Section \\
I04 & A & Police & Patrol Duty Officer \\
I05 & A & Fire Department & District Fire Chief \\
I06 & A & Fire Department & Deputy Head of Control Center \\
I07 & A & Fire Department & Workmanship \\
I24 & A & Fire Department & Head of Control Center \\
I08 & B & Administration & Department Head of Office for Civil Protection \\
I09 & B & Fire Department & Chief Officer / Chief of Fire Dept. \\
I10 & B & Fire Department & Operation Controllers \\
I11 & B & Fire Department & Clerical Grade Watch Department \\
I12 & B & Fire Department & Control Center Dispatcher \\
I13 & B & Fire Department & Head of Control Center \\
I14 & B & Police & Member of the Permanent Staff \\
I15 & B & Police & Head of Control Center \\
I16 & B & Police & Head of Group \\
I18 & both & ENO & Higher Area, High Voltage \\
I19 & both & ENO & Middle Management \\
I20 & both & ENO & Operation Technician, Low Voltage \\
I21 & both & ENO & Dispatcher, Low Voltage \\
I22 & both & ENO & Workmanship Technical Incidents \\
\hline
\end{tabular}

usage; situation illustration and construction; information quality, quantity and trustworthiness; communication practices; cooperation and collaboration; debriefing and learning; citizen involvement. After that, we identified the specific challenges in collaboration practices related to these categories.

\subsection{Empirical results}

Before we describe our findings in the following sections, we will detail the organization of emergency management services in the regions we are concerned with, notably the structure of the police and firefighting services. Firstly we should note that, in the two regions we are concerned with, organizational structures are different. Region B provides professional fire and rescue services, whereas in region A, firefighters are mostly members of volunteer fire departments. Here, in region A, the only professional positions are held by people working in the control center. Secondly, in both regions, firefighters receive their orders from the field via 'incident commands', while police forces in the field receive their commands from the operations management at the control center.

During major crisis situations, crisis management is organized as follows: Germany is separated in 16 federal states and each of these states in turn is 
separated into several counties. The administrative head of the county holds the overall political responsibility for crisis management action. Two types of crisis management groups exist in each county. There is one crisis committee, which is responsible for administration and organization tasks, and consists mainly of permanent staff from the administration office. The administration office includes, for instance, the general county administration, regulatory authority, office for civil protection and several other civil services. In addition, there are several operations management groups, which are responsible for operations during crisis situations and are located in each crisis response organization (e.g. police, fire fighters, etc.). To illustrate the general collaboration practices between crisis response organizations, we will present a short example. Two emergency phone numbers exist in Germany. In case of fire, flooding or medical emergencies, citizens have to call 112 in order to alert the fire department, in other cases 110 to call the police. After calling 112, the fire department will usually take action by executing predefined response plans. The fact that two different emergency numbers exist reveals that emergency response organizations act independently of each other in most normal circumstances. Both organizations are responsible for their own actions and have their own procedures. The only predefined collaboration that exists involves the police ensuring that fire fighters have enough room for e.g. fire trucks at an incident scene. When it comes to a larger incident or even to a crisis situation, however, the operation management groups will include liaison officers from the other involved emergency organizations to plan further actions cooperatively. Besides police and fire fighters, other crisis response organizations exist. However they for the most part just support coping and recovery work. The responsibility for their work remains with the operational management group or crisis committee. The Germany Federal Agency for Technical Relief is an example of such an organization. They can provide specific expertise and technologies to cope with special crisis situations, but they have no decisionmaking power.

Our empirical data revealed to us that improvisation does indeed play a significant role within intra- and inter-organizational collaboration practices, as the literature attests. It is, moreover, is understood by participants to be a normal and routine feature of work of this kind. It therefore has a major influence on information and expertise sharing practices as well. Hence, we describe below why and how improvisation is a key issue and what factors lead to improvisation activities. We will than have a closer look on information retrieval and expertise sharing practices.

\subsubsection{Improvisation in coping and recovery work}

Constantly being faced with new problems and the need to act quickly play a significant role in handling a crisis situation. Our study revealed that in both 
counties coping with unexpected information needs, ad hoc decision-making and coordination is a regular and common practice among decision-makers when responding to uncertain circumstances under risk and with limited time available. Improvisation, in other words, is routinely done:

"Improvisation is essential, next to extensive planning. You can have the best predefined response plans, but there is always a situation, where you have to improvise." (I01) or "We improvise as usual. We see to it that we make the best out of each situation" (I11).

So, besides executing one or more response plans, we could see that in today's emergency management processes straying from plans and predefined actions is common practice: "All workflows are flexible. This is necessary, because each situation is different" (I02). Hence, the uniqueness of each crisis situation and the resulting ad hoc information retrieving practices form the basis of the situation assessment work of each organization. A wide range of emergency response actions also demonstrates that improvisation is usually a collaborative task. To deal with an uncertain and changing environment during crisis situations, a great number of people are involved in gathering and analyzing data, decision-making and monitoring of implementations and consequences. The following extracts indicate the way in which these practices might be structured. The first shows why what we are calling 'improvisation' is so important:

"This is necessary, because no situation is equal to any other. [...] Our work is fundamentally different from other local authorities. There are no predefined processes we are working off - we would be helpless and lost. That's why we tactically work with mission-type tactics" (I02).

The point here is that no single situation can be assumed to be like others that have preceded it. This has some obvious ramifications, as is stated, for procedure. Responses, as is suggested here, need to be 'tactical' rather than strategic. Actions will be ordered specifically in the light of unfolding real-time events, rather than through assumptions about what such events typically entail.

What will follow from this is, again, evident. There is an urgent need for up-todate and accurate information about what has occurred. Nevertheless, outdated information, e.g. phone numbers or contact persons, may exist. The picture of the situation - some kind of overall assessment - is necessary before any coordinative activities are possible. Put simply, coordination has to take place at a 'command' level before coordination can take place at an operational level. As a policeman on operational level said:

"We have to get a picture of the scene at first. Than we both have to coordinate ourselves: finding appropriate ways of solving the problem together and then running these actions" (I04). 
In addition, a member of a command center of an ENO said:

"But if it's critical anywhere, you will willingly ask a colleague: 'What do you think about it? Give it the once-over.' The big advantage we have is that there are at least two of us sitting here, twenty-four-seven" (I20).

To assess the potential impacts of present or future events, members of the group (usually emergency services) share their knowledge within the group or depending on the case - they have to consult external experts (e.g. members of the residents' registration office to access, for instance, numbers of occupants in case of a burning house).

\subsubsection{Situation assessment practices}

We have seen that no two situations are identical (or even similar) and, as a consequence, predefined response plans are not especially useful. These circumstances lead to further reasons for ad hoc decision-making and spontaneous information retrieving. We will explain this in detail, while having a closer look on organizational and inter-organizational situation assessment practices. Situation assessment, as we have suggested, is a necessary precursor to action in crisis management. The information needed will emanate from several sources and will be accessed through a number of different channels. This will include, for instance, information about staff positions, material resources, weather forecasts, emergency plans and will come from different organizations (e.g. weather services, ENO, etc.) via different media channels (e.g. phone, internet, face-to-face, etc.). During non-routine events this typically takes place in an ad hoc manner. However, current crisis management is such that information provision falls significantly short of what is needed. Not only is information sometimes missing but actors often do not even know what data other (or even the own) organizations are able to provide (it is important to bear in mind that the actors involved in a crisis situation may never have encountered a similar one before).

We were able to identify three factors that influence this. Firstly, as I15 pointed out, organizations usually concentrate on themselves and their work tasks, and not on providing information proactively. This is especially true during major events as a result of time constraints. Secondly, each individual organization may have little conception of what information other organizations might find useful. For example, actors from ENO highlighted the usefulness of information about roadblocks in specific situations to make alternative routing more efficient. This information is mainly provided by the police or the fire department, but it is apparent that they sometimes do not think to send such information through (I16). Thirdly, there is an issue relating to the granularity of information provided. Information, put simply, can be short on necessary detail. In the case of 
infrastructure operations, ENO sometimes provides information with previously missing details such as the number of households affected (I10):

"What has broken down, how much of the energy network is out of work and how many people are affected?"

Information accessibility is also an issue. There are various reasons for this. These include the fact that appropriate interfaces for viewing information are not always available; access to important information is often restricted as a matter of policy (frequently the case with non-publically available databases) and the fact that there are terminological differences in the structuring of information in discrete organizations. It makes the sharing of information for situation assessment even more difficult (W2). "Many terms are different" (I02) and varying descriptions of incidents and situations can cause communication issues. This latter is significant in, for instance, trying to make an assessment of how serious a particular incident may be, as for instance:

"There is a person with a cut finger and an employee from the agency for technical relief reports this injury - This nearly sounded like a fatality!” (W2).

More generally, one of the major challenges when retrieving information about a certain situation is assessing the quality of that information. This, we should recall, in situations where time can be of the essence. Information from the Internet needs to be evaluated carefully and it is often difficult to assess its correctness, truthfulness and relevance (I15). The same applies to other citizengenerated content as there is no common "level of consciousness" (I15) and citizens cannot decide what information is needed by the authorities and other organizations (I02). Quality is equally compromised by the fact that, in times of crisis there can be floods of information that are difficult to manage - it can be duplicated, can be inaccurate and impressionistic, and can be misleading. Even information from official sources, such as alerts in the face of severe weather can contain uncertainties and has to be evaluated carefully. Such warnings are often published too frequently and in many cases no critical weather conditions occur:

"Most of the time, when we put extra staff on demand due to weather alerts, nothing happens. [...] we have the problem, that these warnings are reported to frequently and I cannot put staff on demand for each weather warning" (I02).

These ambiguities mean that direct viewing becomes especially valuable. Additional information resources (e.g. current weather conditions outside the 
building or webcams that are focused against the wind direction), and which give a more immediate 'picture', are used to obtain a better overview of the situation (I24). The point here is that more and more information does not necessarily lead to better information. Rather it can create ambiguity and uncertainty. The kind of 'direct view' we refer to here is a valuable means to reduce that ambiguity (I15). We substantiate these observations by giving an example (see below).

\subsubsection{Information retrieval and exchange processes}

Information retrieval for situation assessment, unsurprisingly, usually begins with a trigger event such as an incoming emergency call or warning message (e.g. severe weather alert). To keep track of the events and to be adequately prepared for an incident, decision-makers have to collect supplementary information from various sources: "You need as much information as possible" (I24). Some of the information (like weather alerts) is provided by "official" information systems or files. In case of a major disaster or a weather alert, these internal information resources are enriched through external and informal information resources (like webcams, water level or traffic services). As we have indicated, emergency services need as much accurate and unambiguous information as possible, but are highly conscious of the fact that this will mean considerable filtering of data sources. Keeping track of several information resources to have an overview of the situation at this early stage is not unproblematic and is compounded by the fact that much of it is gathered individually from the Web. Nevertheless, the speed with which information is available to them seems to override other considerations:

"It turned out that the [...] Internet [is] faster than our officers on-site. [...] The information has admittedly to be evaluated but they were very, very useful concerning the quality. I was impressed by the mass, the speed and the usefulness" (I15).

On-site actors are instructed to "collect and communicate any information that is locally graspable and available" (I07). At the same time, they also depend on an optimal overview of the situation as it develops. Above all, they always need be kept informed by the control center, where all information in theory comes together, is accumulated and then redistributed, either by radio or phone. In addition to that, they often make use of their private smartphones to obtain additional information:

"Some of the colleagues have an Internet connection on their smartphone that is often useful, for example to pull up an aerial image of the locality via Google Maps to check other information" (I04). 
Having said that, retrieving information from other organizations is a major challenge in the control center. As we have said, organizations do not necessarily proactively inform other organizations about further development. They have to be asked directly:

"The other actors have a different perception because they concentrate on their problems and not on providing information" (I15).

Each organization uses their own emergency management and communication systems, developed for their specific organizational needs and which are not directly accessible by other organizations or by the public (W2). Moreover, the different control center systems of e.g. the police and fire department cannot communicate directly one with the other. The control center of the police, for instance, uses a different system for crisis response than the operations management. Furthermore, even at this point it is difficult to share information between these internal units:

"There is no interface between our software system and the control center system. We need to export a PDF-file and send via e-mail to the control center" (I15).

We should also point out that there is a distinct distribution of expertise on the part of users. Some users are technically adept, and will, for instance, bookmark websites with additional information resources, such as webcams, to check weather conditions or the water level status of nearby rivers (because their official system does not provide this information). Others are less so. This means that available information is differentially acquired and, sometimes at least, is available to certain individuals but not to others.

\section{Supporting information and expertise sharing}

The empirical study shows abundantly clearly that certain kinds of information need to be shared quickly, accurately and unambiguously to all relevant operators. At the same time, the flow of information has to be carefully managed so that the 'flood' does not produce the exact opposite. The current organizational and technical structures of each organization involved do not provide suitable interfaces to effect this efficient flow during major incidents, due to the large number of heterogeneous systems. The exchange of information is currently limited to e-mail, phone calls or special liaison officers, who are the on-site contacts of the operations management of the other organizations. The exchange of expertise tends to be dependent on the experience and contacts of longstanding employees. Our findings can be divided in two main areas: (1) interorganizational information sharing and (2) inter-organizational expertise sharing. 
Table 3 shows the challenges for inter-organizational information and expertise sharing, from which we derived the design implications for the conceptual and technical architecture of our approach.

\subsection{Enhancing inter-organizational information sharing}

The literature and empirical study show that due to the highly uncertain and dynamic nature of large-scale incidents, organizationally predefined structures and processes are often not sufficient and ad hoc information retrieval or spontaneous communication becomes much more important. Coping with unexpected information and ad-hoc decision-making require improvisation, which in this sense, means for example that units of one organization will call members of other involved organizations informally and spontaneously. On the one hand, (1) such improvisation work is indispensable while responding to highly dynamic emergencies; on the other hand, it does not guarantee that information will be shared by all those who need it, and it means that the flow of information depends on an adequate distribution of expertise which, again, cannot be guaranteed under the current arrangements. The fact that improvisation work in emergencies often prevail the fixed organizational work structures implicates the need for ad hoc communication and spontaneous information retrieval.

At the same time, each of these respective organizations needs to be able to fulfill its respective tasks and routine procedures under normal circumstances, and therefore needs its own individual, specialized systems and organizational structures. Besides phone calls or e-mails, which are fallbacks due to the dynamics of a situation, (2) the landscape of heterogeneous systems and organizational structures offer only inadequate possibilities for accurate, consistent and up-to-date inter-organizational communication. The design challenge would not be to replace existing systems through a comprehensive "integrated" solution or as mentioned above to break up the current organizational structures, but to create interfaces between the different systems and to provide additional opportunities for inter-organizational communication and information exchange to design the systems more flexible. To connect the diverse individual systems, a web-based, service-oriented architecture is needed since it offers platform-independent access that can act as a light-weight intermediary between the different interfaces.

Beside the aforementioned challenge of providing a more flexible technical (software) level, challenges also exist on an organizational information level. In information retrieval and exchange, the organizations are aware that their information is not only relevant for their own individual work, but also - in principle - for other organizations. For example, police road barriers have an enormous impact on the driving routes of aid agencies or fire departments to the location of the incident. However, due to the fact that emergencies evolve 
Table 3. Empirical study-based design implications.

\begin{tabular}{|c|c|c|c|}
\hline No. & $\begin{array}{l}\text { Empirical findings } \\
\text { (related to section } 4 \text { ) }\end{array}$ & $\begin{array}{l}\text { Inter-organizational } \\
\text { Challenges }\end{array}$ & Design implications \\
\hline \multicolumn{4}{|c|}{ Inter-organizational Information sharing } \\
\hline 1 & $\begin{array}{l}\text { Besides fixed organizational } \\
\text { processes, improvisation is } \\
\text { very important (section 4.2.1) }\end{array}$ & $\begin{array}{l}\text { Complement fixed } \\
\text { processes and capability } \\
\text { for improvisation } \\
\text { practices }\end{array}$ & $\begin{array}{l}\text { Functionality for ad hoc } \\
\text { communication and } \\
\text { information retrieval }\end{array}$ \\
\hline 2 & $\begin{array}{l}\text { Heterogonous, specialized } \\
\text { communication systems at } \\
\text { each organization }(4.2 .3)\end{array}$ & $\begin{array}{l}\text { System-independent } \\
\text { additional inter- } \\
\text { organizational } \\
\text { communication options }\end{array}$ & $\begin{array}{l}\text { Web-based architecture } \\
\text { to facilitate system } \\
\text { independent access }\end{array}$ \\
\hline 3 & $\begin{array}{l}\text { Lack of knowledge about } \\
\text { available data at the own or } \\
\text { other organizations (4.2.2) }\end{array}$ & $\begin{array}{l}\text { Capability to structure } \\
\text { available data }\end{array}$ & $\begin{array}{l}\text { Meta-information about } \\
\text { suitable and available } \\
\text { data }\end{array}$ \\
\hline 4 & $\begin{array}{l}\text { Large amount of required } \\
\text { information }(4.2 .2)\end{array}$ & $\begin{array}{l}\text { Capability to aggregate } \\
\text { and structure information }\end{array}$ & Additional meta-attributes \\
\hline 5 & $\begin{array}{l}\text { Required information is } \\
\text { mostly organizational } \\
\text { distributed (4.2.2) }\end{array}$ & $\begin{array}{l}\text { Capability to access } \\
\text { information centrally }\end{array}$ & $\begin{array}{l}\text { Shared inter-organizational } \\
\text { information repository }\end{array}$ \\
\hline 6 & $\begin{array}{l}\text { Out-of-date information, e.g. } \\
\text { phone numbers, contact } \\
\text { persons }(4.2 .1)\end{array}$ & $\begin{array}{l}\text { Capability to keep } \\
\text { information as up-to-date } \\
\text { as possible }\end{array}$ & $\begin{array}{l}\text { Decentralized, shared } \\
\text { information maintenance }\end{array}$ \\
\hline \multicolumn{4}{|c|}{ Inter-organizational expertise sharing } \\
\hline 7 & $\begin{array}{l}\text { Accessibility and policy } \\
\text { issues between } \\
\text { organizations (4.2.2) }\end{array}$ & $\begin{array}{l}\text { Capability to provide } \\
\text { tactical and operational } \\
\text { accessibility }\end{array}$ & $\begin{array}{l}\text { Authentication and } \\
\text { individual sharing }\end{array}$ \\
\hline 8 & $\begin{array}{l}\text { Terminological differences } \\
\text { between organizations } \\
(4.2 .2)\end{array}$ & $\begin{array}{l}\text { Overcoming verbal } \\
\text { terminology differences }\end{array}$ & $\begin{array}{l}\text { Verbal communication } \\
\text { with visualizations } \\
\text { functionality }\end{array}$ \\
\hline 9 & $\begin{array}{l}\text { Difficult inter-organizational } \\
\text { situation assessment (4.2.2) }\end{array}$ & $\begin{array}{l}\text { Enable inter-organizational } \\
\text { situation assessment }\end{array}$ & $\begin{array}{l}\text { Shared inter-organizational } \\
\text { situation map }\end{array}$ \\
\hline 10 & $\begin{array}{l}\text { Information overloaded } \\
\text { situation maps }(4.2 .3)\end{array}$ & $\begin{array}{l}\text { Reducing overload on } \\
\text { situation maps }\end{array}$ & Individual map layers \\
\hline 11 & $\begin{array}{l}\text { Spatially distributed teams } \\
\text { and organizations during } \\
\text { response work }(4.2 .1)\end{array}$ & $\begin{array}{l}\text { Enable location- } \\
\text { independent inter- } \\
\text { organizational collaboration }\end{array}$ & $\begin{array}{l}\text { Location- and time- } \\
\text { independent collaboration } \\
\text { functionalities }\end{array}$ \\
\hline
\end{tabular}

unpredictably and that organizational members often miss detailed insight into other work practices and structures, (3) the knowledge of what information is available within one's own organization, as well as the knowledge of which piece of information is relevant at what time for which organization, is very hard to predict and is often dependent on many years of individual experience. The current systems lack instruments to distribute meta-information about the overall process and suitable and available information as well as to articulate information demands in order to share information with other organizations. The dynamics of 
an emergency make it hard to predict all the information needs of other organizations in advance. Instead of trying to anticipate these information demands, we argue that organizations should proactively provide information with supplementary meta-information automatically added, even if they are not aware of how this information could be used of other organizations. In this way, even inexperienced actors from other organizations would be able to search through the available information and would be able to access it easily.

Associated with this, we suggest that, in order to deal with the problem of the (4) large amount of (5) external information and its distribution to individual organizations, centralized access to decentralized information sources should be provided. A central access point with standardized interfaces enable organizations to know where and how they can access information from other organizations. Technically, the central access point as well as the offer of meta-attributes can be realized by a shared, web-based information repository. The decentralized maintenance of the individual information and its meta-attributes in the repository could prevent the necessity of having to deal with (6) outdated information, since each organization is responsible for the timeliness of the provided information.

\subsection{Enhancing inter-organizational expertise sharing}

Due to the spatial distribution of organizations involved in response work, the current practice lacks options for inter-organizational collaboration or expertise sharing. Apart from one-to-one phone calls, which mainly depend on knowing who to contact when from which organization, it is hard to collaborate among spatially distributed actors from different organizations. Even inside one organization the collaboration between on-site units and the staff at the control center is limited to speech and radio. It is not always obvious which person is the right one to contact or how to contact him. The challenge is to provide location-independent functionalities that simplify the current needs for inter-organizational collaboration. Further, accessibility, (7) legal regulations and policy issues limit cooperation between the various organizations. Coordination at present takes place on a political and strategic level, regulated through the legal agreements. In order to manage incidents successfully, especially large-scale emergencies, organizations are challenged to come together on several organizational levels. To pave the way for collaboration not only on a strategic level that is mandated by law, but also spontaneous on a tactical as well as operational level, authentication mechanisms are required across all organizations, which foster individual fine-granular expertise sharing. The information needs of other organizations are rarely trivial - especially, as is often the case, for inexperienced forces. Equally, their operational processes are opaque for the outsider. Regular sharing on a tactical and operational level, then, should help units to dovetail with the work practices of other forces. 
As we have suggested, inter-organizational (and even intra-organizational, such as between control center, operations management and crisis committee) communication is bedeviled by (8) inconsistent technical terminology. For example police and fire services do not share a common understanding of the term "large-scale emergency", which implicates different measures for each organization. Such terminological differences make it difficult to collaborate and share expertise among the various domains (Reuter et al. 2012b). Legislating vocabulary, however, comes with problems of its own (see e.g. Martin et al. 2007) as operators can be sometimes forced into artificial and ambiguous categories when confronted with unusual circumstances. Our proposed solution involves visualization techniques that operate with icons and images instead of exact descriptions or terms. At the time of writing, (9) no inter-organizational situation assessment takes place. During a large-scale incident each organization operates in its own control room as well as (10) onsite with a situation map, a "map showing the tactical or the administrative situation at a particular time" (US Department of Defense 2010). Based on such a situation map, operation goals and concrete measures are derived by the respective organization. The challenge of establishing a common assessment of the situation must therefore include the possibility of a shared situation map (closely connected to the terminology issue) or a means to integrate information on the different maps, so the situation can be visualized and discussed as it unfolds.

One of the difficulties is that (11) each situation map in the respective organizations is often already overloaded. It already contains all tactical aspects and resources like units, the strength of unit groups, situationally important buildings as well as search radii or collecting points. It is apparent that simply adding more information in will create an additional load on 'readability'. Map layering is a well-known solution to this kind of problem in GIS and is commonly used to examine scenarios in planning environments (see for instance Klosterman 1999). In this manner, all relevant information is preserved but maps can be tailored at any given moment to meet specific organizational needs. At the same time, further work will be needed concerning how exactly maps are being used in order to populate the layers with adequate, elegantly ordered, information.

\subsection{Architecture overview}

Based on the challenges that emerged in our empirical study and the design implications derived from it, we developed a system addressing the interorganizational information and expertise sharing. To foster inter-organizational information and expertise sharing, we must also pay attention to the heterogeneous software systems at each organization. We decided therefore to set up a web-based, service-oriented architecture to enable a system which exists outside 
the existing, organizational ICT and to offer an independent access. Our system consists of the two main modules Inter-Organizational Information Repository (IOIR) and Inter-Organizational Situation Assessment Client (ISAC) (Figure 1).

We decided to design a web-based, service-oriented architecture to enable collaboration especially on an inter-organizational level, independent of the individual technical infrastructures and systems of the responsible organizations. ISAC is designed as a situation map and allows various collaborative and sharing interactions. To allow situation assessment with mobile spatially distributed units, we also developed a mobile version of ISAC (Reuter and Ritzkatis 2013; Reuter et al. 2014). IOIR is designed as a web-based information pool, which gives central access to distributed, external information resources like websites, files or various web services and provides interfaces to the control center software of each organization.

\subsection{Inter-Organizational Situation Assessment Client (ISAC)}

The fact that problems of accessibility as well as legal and policy restrictions exist is an obvious justification for our web-based service. At the same time, enabling inter-organizational coordination on the tactical and operational level requires an inter-organizational authentication service for each actor of the respective organization. On the tactical and operational level, the core tool of each organization is its own situation map for situation assessment. Therefore we designed an inter-organizational situation map.

We developed ISAC (Figure 2), which is based on Google Maps and offers the user different options for adding, changing, sharing or deleting information on the map. The information can be represented by markers, locations, polygons, circles or free-hand drawings. After logging in, the user sees on the left the information tree that is structured through different main categories like weather, traffic, important locations or private information (1).

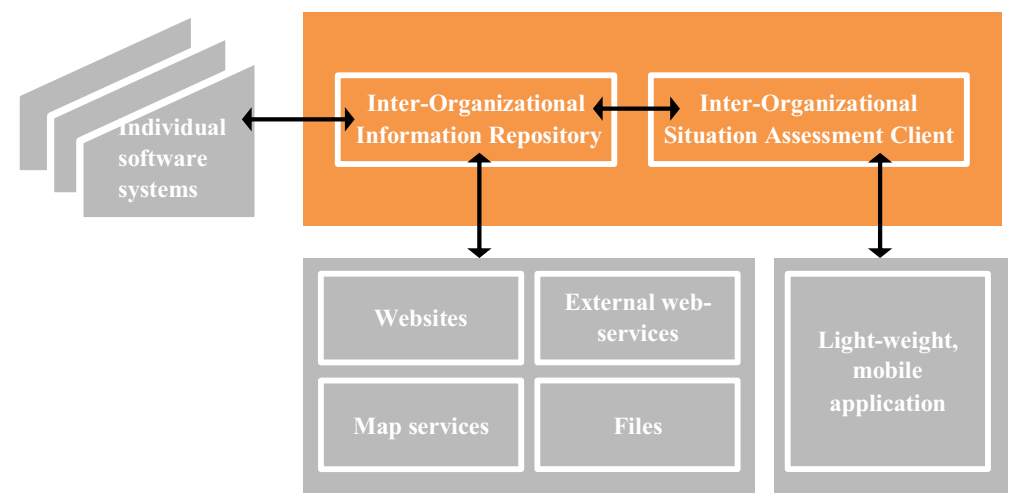

Figure 1. Technical System architecture. 


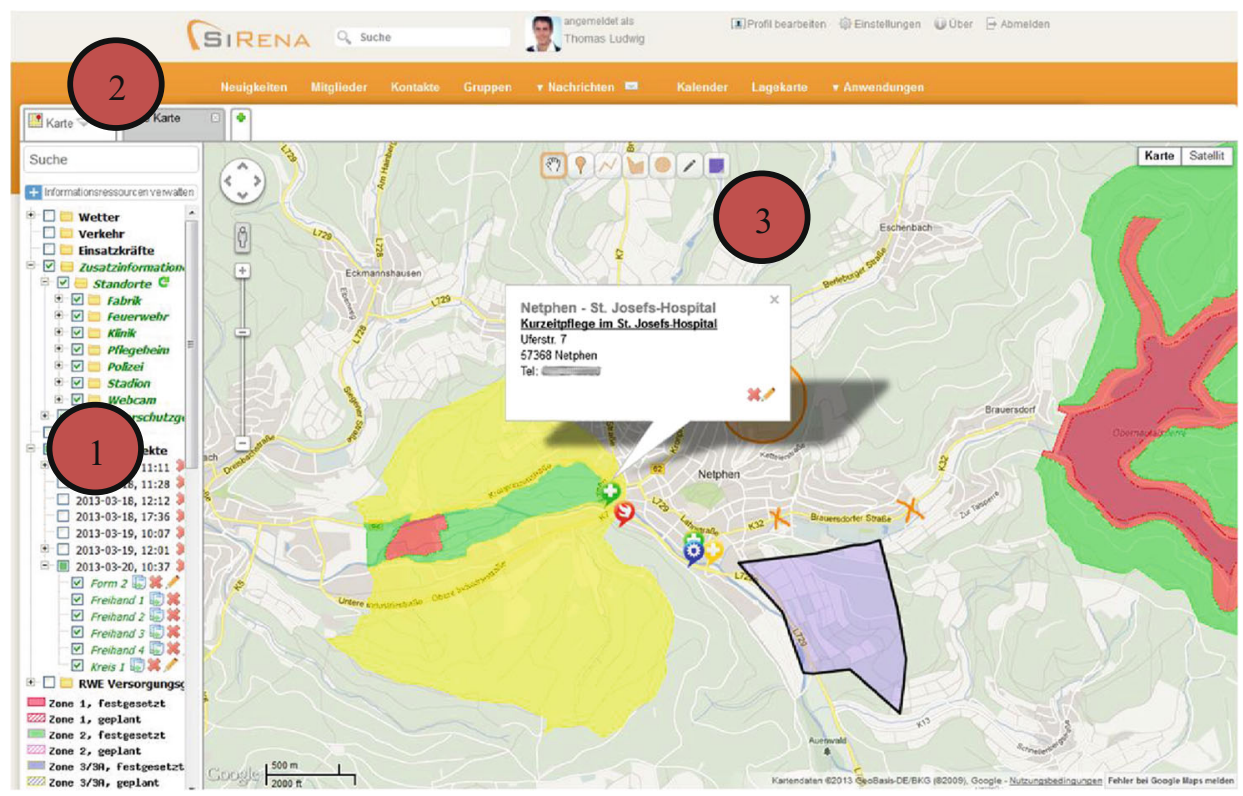

Figure 2. Inter-organizational situation assessment client.

The information is structured by the inter-organizational information repository (section 5.5). To avoid information overload on the map, such information can be shown individually or it can be hidden or collected in different map layers. The tab-based map allows a person to create, label and save multiple maps to have them available on-time in different real emergencies (2). For example, one map can be prepared for a flood scenario with the necessary information like water levels and past flood areas, another map for the evacuation of a hospital with the necessary information like the local hospitals or shelters. The creating, changing and deleting of such information is described in the next section. Beside this information, additionally, annotations such as circles, polygons or free-hand drawings can be inserted to mark special, mainly temporary locations or situations, e.g. road blocks or collecting-points during operations (3). These annotations are declared as private objects that allow a person making personal drawings or short marks in addition to the general shared information on the left side.

It is also likely that multiple people will need to collaborate synchronously on a situation map during a crisis. To enable collaborative editing - necessary when rapid situation updates are required - we developed a WebSocket-based collaboration mode allowing a bi-directional, full-duplex communication. This collaboration mode lets the user make changes on his current map and everyone invited to his session can see the changes made at the same time. The initiator of a session has the option of assigning writing access to any of the invited 
participants or forcing them back. So, ISAC supports and fosters real-time interorganizational discussions around a situation and at the same time deriving tasks from the overall operation for one's own organization through the interorganizational visualization/map-based functionalities like the collaboration mode or the display of external information. For the distributed situation assessment between on-site forces and those in the organizations' control centers, we developed a light mobile version of ISAC with the same functionality, but adapted for the small screens of smartphones and tablets.

\subsection{Inter-Organizational Information Repository (IOIR)}

The IOIR (Figure 3) which gives central access to distributed, external information that is otherwise not available to certain organizations. Through this module, organizations do not have to extensively search the web or call people from other organizations for every required bit of information. They have a webbased central access point to information resources, where the data is stored on servers of the respective organizations. These are responsible for the maintenance of this information (e.g. accuracy or timeliness), thus outdated contact information or phone numbers can be avoided. The repository makes integrating, creating, modifying and deleting information resource references possible. When

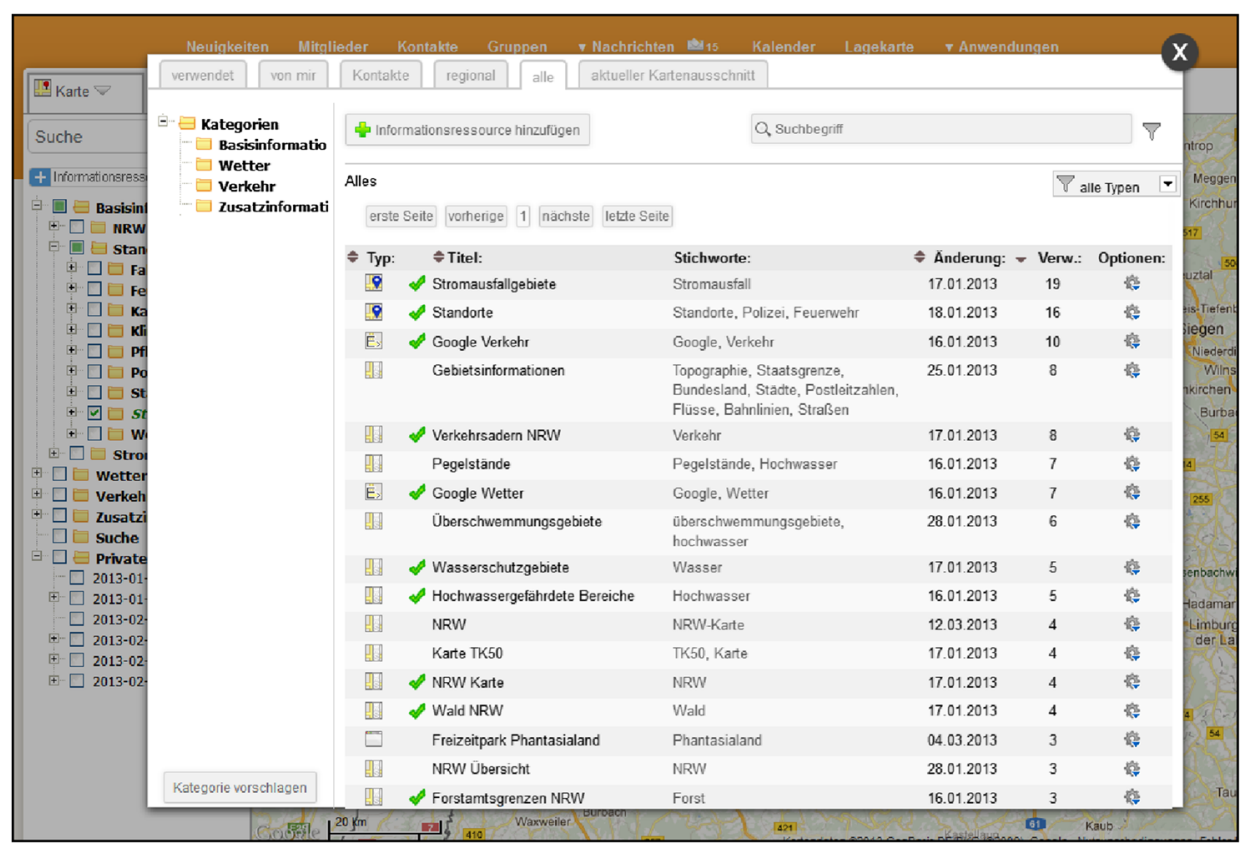

Figure 3. Inter-organizational information repository. 
adding an information resource, labels can be appended to identify a specific type of information (e.g. website, $\mathrm{OGC}^{2}$ specified web map service, documents, etc.), keywords can be added and it can also be allocated to a general category. The information from IOIR that has a geographic reference can be shown on ISAC. In return, all the public information from ISAC is directly stored in IOIR.

Based on meta-attributes like type (Figure 3 in German: 'Typ'), title ('Titel') or keywords ('Stichworte') information resources can be adequately filtered. For additional filter mechanisms, the user has the choice of filtering information according to what is used by his contacts or the frequency of use according to others. Every information resource has comment functionalities, where users of all organizations can discuss the use, the content or the relevance of an information resource. Such functionality fosters an inter-organizational view on the same resource. By developing IOIR, a kind of central directory for web-based information resources has been created, which can be an opportunity for interorganizational, collaborative information sharing.

\section{Evaluation of ISAC and IOIR}

The prototypes described in section 5 were designed, implemented and evaluated in two iterations with a particular focus on information and expertise sharing practices. After the first cycle, we conducted a formative evaluation based on scenario-based user tests and after the second cycle -1.5 years later - the redesigned and improved system was rolled out for a field test under real-use conditions. Additional interviews with participating users were conducted 35 weeks after the roll out. Participants in the evaluations are listed in Table 4 and 5. In the following, we will describe the method used and the results of both evaluations.

\subsection{Evaluation I: Scenario-Based User Tests}

The aim of the formative evaluation was to get user feedback about the general system design, possible use cases and accompanied design limitations, with the intention of feeding back into the development of the second prototype early on. The functionality of the first prototype was still limited and unsuitable for real-use testing, so we chose a scenario-based user testing under controlled conditions. The tests were conducted at the users' workplaces and lasted between 1 and 1.5 hours. Twelve users participated in the study (see Table 4). At the beginning of the test, the prototype and its basic functionality were briefly introduced to the participants. In the next step they had to use the system independently and solve

\footnotetext{
${ }^{2}$ The Open Geospatial Consortium (OGC) is an international industry association for developing publicly available interface standards.
} 
Table 4. Participants evaluation I.

\begin{tabular}{llll}
\hline No & County & Org. & Role \\
\hline E01 & A & Police & Head of Control Center \\
E02 & A & Police & Head of Section \\
E03 & A & Fire Dept. & Deputy Head of Control Center \\
E04 & A & Fire Dept. & Head of Control Center \\
E05 & both & ENO & Operation Engineer, High Voltage \\
E06 & both & ENO & Operation Technician, Low Voltage \\
E07 & both & ENO & Higher Area, High Voltage \\
E08 & B & Police & Head of Control Center \\
E09 & B & Police & Head of Group \\
E10 & B & Fire Dept. & Head of Control Center \\
E11 & B & Fire Dept. & Watch Department Officer \\
E12 & B & Fire Dept. & Head of Group \\
\hline
\end{tabular}

predefined tasks. Participants were asked to think aloud (Nielsen 1993) and comment on their actions to be able to track and understand possible design and usability issues. In a subsequent semi-structured interview they were asked about their personal experience and assessment concerning their first impression; individual system description; system handling; conceivable use cases in personal work context; requirements to make the system usable; collaborative situation assessment; and further information needs. For the most part, feedback concerned usability issues. These were incorporated into the final design mentioned in section 5 and are not discussed here further. More importantly, the formative

Table 5. Participants evaluation II.

\begin{tabular}{llll}
\hline No & County & Org. & Role \\
\hline E13 & A & Red Cross & County Head \\
E14 & A & Fire Dept. & Administrator Control Center \\
E15 & A & Fire Dept. & Staff of Control Center \\
E16 & A & Fire Dept. & Head of Fire Department \\
E17 & A & Police & Head of Section \\
E18 & A & Police & Staff of Control Center \\
E19 & A & Police & Staff of Control Center \\
E20 & A & Police & Staff of Control Center \\
E21 & A & Police & Head of Control Center \\
E22 & both & ENO & Operation Engineer, High Voltage \\
E23 & both & ENO & Operation Engineer, High Voltage \\
E24 & B & Police & Staff of Control Center \\
E25 & B & Police & Data Administration, Control Center \\
E26 & B & Police & Staff of Control Center \\
E27 & B & Fire Dept. & Workmanship \\
E28 & B & Fire Dept. & Staff of Control Center \\
\hline
\end{tabular}


evaluation gave us valuable feedback concerning how information can be shared with others. The initial design concept enabled users to compile and prepare their individual maps by letting them add relevant information. These compilations could then be made available to other users. However, it became clear that this kind of sharing was not suitable for situational purposes during a crisis situation, as it did not make a direct exchange between the involved actors possible. In this context, the participants expected a synchronous map sharing and annotation tool, so that they could have the same view of the situation and thus a common basis for discussion. These limitations were also taken into consideration during the second design cycle and were implemented in the final prototype.

\subsection{Evaluation II: field test}

Based on the feedback from the user tests we redesigned and improved the prototype. After that, our aim was to conduct a field test with 16 users from different organizations (see Table 5). We organized a roll out workshop for each participating organization, where we gave participants their login data and a brief introduction into the system and its use. Both the situation assessment client and the information repository were released to the users for unrestricted use. After a 3-5 week evaluation period, we arranged and conducted semi-structured interviews with the participating users to find out if the system was usable under real-use conditions and what the conceivable use cases were. Most of the interviews were conducted individually and lasted between 30-45 min. Two interviews were group interviews (police and fire department in region A). Those group interviews lasted about 60 min each. The guideline covered 5 main topics:

1. Information about the interviewee, his/her role and qualification.

2. General questions about the usability of system and the user's first impression.

3. Analysis of the usage context, which tasks were performed, who was involved?

4. Inter-organizational use, which organizations could be involved, which information would be shared and which not, what are the chances and challenges when sharing information with other organizations?

5. Prospective, what is necessary to use the system during daily routine, what additional functionality is desired?

Each interview session was audio-recorded and transcribed for subsequent analysis, which was divided into three steps (Schmidt 2004):

1. The transcripts were structured according to the questions of the interview guideline. Statements taken from the transcripts shed light on participants' reactions during the session. 
2. Based on the transcripts, ex-post categories were formed for the analysis. This categorization included aspects about the implementation and integration of the system with existing infrastructures and practices in the application domain, shared content and collaboration scenarios, information visibility concerns in inter-organizational information and expertise sharing, and recommendations for improvements.

3. These analytical categories were used to create a coding guideline. It helped to cluster the data in terms of meaningful units to focus on specific problems.

It turned out that the system was used by every participant, but not, for the most part, in real-work contexts as anticipated. The main reasons for this are described in detail in the following section. This is a common problem with field tests (see e.g. Hertzum et al. 2012) and needs to be considered as a limitation of the study. Nevertheless, the evaluation reveals some valuable results about the system's usability, possible use cases, and information sharing practices with other organizations.

\subsubsection{Integration with existing infrastructures and usages/practices}

Above all, we were interested in whether and how the application might be used in real-world conditions during the evaluation period and how the system might support the participant in a specific situation. Unfortunately, only a few participants really used the system in that fashion. One central problem we had to deal with was that some organizations did not provide the necessary ICT infrastructure to run our system fluently. More precisely, the installed web browsers in the control centers were outdated (e.g. one police station is still using Internet Explorer 6, which was released in 2001) and did not support important computer technology like JavaScript or Web-Sockets, which are necessary to run our application. This meant that the prototype could not be used at some participants' workplaces during the evaluation period. Although the participants had access to a stand-alone computer where a suitable web browser was installed, the use was not feasible in work context:

"I don't have the opportunity to sit there [at the stand alone computer], because if I am involved in an operation, I can't stand up and leave my workplace" (E26).

Another issue that stood in the way of use was the lack of information. Although the predefined information resources could give a sufficient overview of the system's functionality, they did not cover the entire amount of information which was already available in existing geographical information systems:

"Basically we have everything in our GIS. When I am in an operation and have my GIS on the screen, why should I open another GIS?" (E25). 
Although it is possible to add new information resources and thus transfer information from an existing GIS to our system, users saw this as only for testing purposes, because they had no certainty of a long-term application of the system. In addition to that, participants saw a major challenge in the distribution of system information. They argued that a useful application is only possible if

"it is used by everybody and if it is accessibly to everybody. It must not be used in a voluntary manner but has to be an inherent part of our work" (E26).

Of course, in an evaluation scenario of the kind we were undertaking, such universality is impossible. Nevertheless, it strongly points to the organizational changes that are needed if such systems are to be used in real-world contexts.

\subsubsection{Shared content and collaboration scenarios}

Regardless of those limitations, all of the participants were able to explore the system during the evaluation period, be it on their work computer or at standalone computers at work or at home, and could reflect on possible use cases for their individual work practices. In the case of the fire department, they actually used it for example to share information during a breakdown of a major telecommunication operator caused by a big fire in its distributing center:

"I have drawn a circle which represented the exclusion zone and several markers which represented places, where people were led to after evacuation" (E14).

These collaborations, participants realized, also had the potential to create better information for the population:

"With such tools we should have the possibility to create a map which can be easily made public, so that citizens can also create an overview and see, for instance, current roadblocks" (E16).

Information exchange among different support agencies (e.g. Red Cross and fire department), for instance with respect to information about areas where citizens have been informed about a major incident, was seen as a suitable use case with such tools (E13). The control center points out:

"We have to organize and inform the aid agencies, so that they do not work too independently, that's a typical problem we always have; [...] we have to be able to lead them" (E15) - "therefore the map can act as an instructional object" (E16).

In the case of the police, there is currently no system to acquire and visualize roadblocks. Thus, during the evaluation period, one participant explored the 
system by adding current roadblocks to the map. Participants from other organizations also perceived these roadblocks and considered them to be very useful. It became clear that especially the sharing of information or sharing a situation map with other organizations (e.g. between control centers of police, fire department and crisis squads) or with spatially divided members of the own organization (e.g. between control center and forces on-site) is of great interest:

"I think there is a real chance to involve people into a situation, who were previously left out. Because this is something that our system here cannot handle" (E16). Or: "Breakdowns don't only occur during office hours. In specific situations we call our boss or the public relations department. [...] Based on such a map I could show specific information, highlight something, and say: 'Here is this and that problem"' (E23).

This is relevant not only to the synchronous sharing functionality, but also to handovers during a shift change (the problem of information transfer during handover is dealt with in a range of literatures covering, for instance air traffic control, nursing, etc.; see Kerr (2002) for an example):

"Such visualization is helpful for shift changes. It is much better than thrusting a stack of paper in someone's hand, with information about the whole procedure" (E21).

Participants saw the additional value of the system primarily in the visualization of a bigger picture in major incidents and disasters:

"It would be good to have the same map here [control center] and in the command vehicle. [...] But just in bigger situations with a duration of several days, not in case of simple room fires" (E28).

"It would be good for bigger operations, to quickly create a situation overview [...] The only possibility is to work together - fire department, Malteser [human aid agency in Germany] and red cross - the breakdown of the telecommunication operator showed that again. In cases like that I could mark an area on the map and share it to express, that I will take care of that area" (E13).

For situations of imminent danger, however, the system was less feasible:

"Here the system is too sluggish. The situation is different for incidences that evolve over multiple days, like a flood. For this it is a fantastic thing" (E17). 
Although participants mentioned that adding information to the application was easy to manage, it became clear that this process was extremely timeconsuming and could not be done in stress situations:

"When I work here in the control center and there is a major situation and besides that I have to answer 10 or 15 emergency calls, I don't think that anyone has the time to work with it" (E25).

Even if the situation calms down, it is a challenge to maintain the situation map subsequently because "the information from the beginning of the situation is tied to the heads of the staff and not written down anywhere" (E17). The main issue here is the effort that is necessary to add information to the map. This, we feel, is less a usability issue than a lack of predefined templates, shapes, and tactical signs. At the moment, every place mark a user wants to add to the map has to be created from scratch and recurring signs or shapes have to be redrawn de novo:

"As an example, we have predefined roadblocks for every chemical plant. In case of a gas leak, we have to man these place marks. [...] This could be prepared beforehand. [...] or collecting points, like this parking area. I know it has a capacity of 30 vehicles and that can be prepared. For me it is important that I don't have to start every situation from scratch" (E24).

Besides better preparation and faster embedding of information into the map, predefined shapes or tactical signs would also help to get a common understanding of a situation without additional comments:

"There must be a uniqueness to such signs, thus it would be great if you could use tactical signs, so that every leader could read and interpret these signs. [...]

I wouldn't have lot of annotation work if I had these tactical signs" (E13).

Another reason to use predefined and uniform shapes is easier comparability and easier assemblage of multiple maps. For example, in case of a predicted the spreading of a gas cloud after a chemical accident, "it would be interesting if the assessment of the fire department is equal to ours or if there is need for coordination" (E24). For this purpose, both organizations could share their maps and lay one on top of the other to compare possible deviations.

\subsubsection{Information Visibility Concerns in Inter-Organizational Information Sharing}

For security reasons, current ICT infrastructures at the participating organizations are characterized by full isolation. With this in view, it was particularly interesting for us to find out something about the willingness to share (internal) information 
with other organizations. The interviews emphasized that basically there were no concerns about sharing information with others, neither from the police nor the fire department or any other involved organization:

"During a major situation we have to exchange information. In this case we dispatch a liaison officer to them [fire department] and they send one to us. From then on there are no more secrets anyway" (E24).

However, especially in police work, there is confidential information that has to be kept under wraps. This kind of information, it turns out, would not be shared anyway, neither via our application nor via phone or by radio:

"For example during a violent demonstration we also work together with fire department and ambulance services. But there is tactical information on the police side that will not get to the outside. [...] Every operation where special forces are involved" (E21).

With our system, a certain apprehension arose due to uncertainty that specific information could not be handled confidentially enough if too many persons had access to it:

"Especially in the case of pictures we would be very careful because we know that one or two [people] have good relations to the press and would leak them" (E24).

However, general access restrictions would also obstruct desired and legitimized access to information, so that it might be sufficient to make access a visible matter:

"It might be interesting to see who actually looked at the picture, which suddenly appeared in a newspaper. Otherwise we have to restrict the content we add to the system" (E24).

Apart from that, access constraints were only deemed to be useful to restrict the available information resources from displaying irrelevant data. However, this is not motivated by data security reasons but to keep the system and the displayed information clear:

"If it is sometime established statewide, [...] we have to foster further restrictions $[\ldots]$ that I don't have to know what happened in city A, B or C. That everybody only sees information from his own region" (E26).

Current practices are limited a single situation map in the control center restrict access based on the physical presence in the control room, and so participants 
have little experience of managing access control. While using digital representations, which can be shared among the users, new possibilities and questions will arise (E16), including for instance decisions concerning role-based access restrictions, free access for all emergency services or explicit sharing of information.

\section{Discussion}

In contradistinction to many other approaches that develop ICT support for crisis management, we did not focus on one particular organization and its anticipated routines or on one particular activity (e.g. resource allocation, triage). We focused on the necessities of improvisation in a crisis situation where unfolding events cannot always be anticipated, events which are volatile in terms of actors involved and the external factors guiding behavior. Almost every actor needs information about the current situation and its development, but also produces information that could be of interest to others. We therefore focused on the issue of improvisation practices in information and expertise sharing at the interorganizational level.

\subsection{Improvisation practices in information and expertise sharing}

The empirical study of information and expertise sharing practices by the emergency services (section 4) highlighted the specific ways in which improvisation techniques were brought to bear on coping and recovery work, situation assessment and information retrieval and exchange processes. Our findings indicate that inter-organizational communication and cooperation is necessary, but the current organizational and technical structures of each organization involved do not provide suitable interfaces. Due to the large number of heterogeneous systems, the exchange of information is limited to e-mail, phone calls or special trained liaison officers. The exchange of expertise is currently limited, for the most part, to contacts between long-standing employees. There is, in other words, a very unequal social distribution of expertise. While describing the practices in inter-organizational crisis management in detail, these findings confirm and extend the research opportunities in the area of "collaborative knowledge bases" mentioned by Turoff et al. (2004) as well the "unresolved issue [which] is the need for close relationships between those improvising" as mentioned by Cunha et al. (1999).

\subsection{Advances in improvisation support}

Based on the challenges that emerged in our empirical study and the design implications derived from it, we developed a socio-technical system addressing the practice of inter-organizational information and expertise sharing in two iterations (section 5). We set up a web-based, service-oriented architecture to 
enable a system independent access. While the first iteration focused on situation assessment, the second iteration also includes inter-organizational collaboration functionalities. Our lightweight infrastructure, usable with any web browser, and the specialized mobile app consists of the two main interconnected modules Inter-Organizational Information Repository (IOIR), a central access to distributed, internal and external information, and Inter-Organizational Situation Assessment Client (ISAC), a geo-collaborative application supporting ad hoc information and expertise sharing. Our modules enhance the work of $\mathrm{Wu}$ et al. (2013), whose system focuses on one specific geo-collaboration task or Monares et al. (2011), who just focus on mobile collaboration.

\subsection{Evaluation and methodological issues}

In the evaluation of the system (section 6), the formative evaluation after the first cycle led to a redesigned and improved system that was rolled out for a field test under real-use conditions: The summative evaluation outlined challenges related to integration with existing infrastructures and usages, scenarios for shared content and collaboration (e.g. exchanging roadblocks, enhancing situation assessment or collaboration outside the control center) as well as information visibility concerns in inter-organizational information sharing. Our study showed that our concepts and implementations support the emerging inter-organizational information infrastructure acting as an intermediary between the existing discrete ICT systems in the participating organizations. However, our incremental development process has not finished. Certain limitations, as described above, have been identified and we are continuing our evaluations in the field and the respective developments.

We are not the first to realize, but we strongly support the view, that real-time, real-world analysis and evaluation of crisis management is difficult, not to say impossible. Neither our initial studies, nor our prototype could be founded on classic forms of ethnographic study, for the reasons we rehearse above. Nevertheless, our study was conducted with a commitment to getting as close to real-world practices as possible, and to this end we conducted scenario-based interviews both with individuals and with groups. Compared to Convertino et al. (2011) and with respect to the concern that "existing geospatial information technologies [...] have been designed for use by individuals" (Cai 2005), we believe that our work comes closer to real-world analysis than most. In so doing we are not suggesting that we have discovered the fact of improvisation. Rather, we were and are interested in the precise ways in which improvising work is done, and the limitations that are placed on it by existing socio-technical infrastructures. In this respect we have moved the discussion on from the interests of management science (e.g. Weick 1993) which has tended towards post hoc understandings of previous disasters towards analysis of the prospective. 


\subsection{Architectural considerations}

All organizational actors already use own kinds of ICT infrastructure, usually protected against foreseeable emergencies caused by power outages (e.g. batteries, redundant command stands), hacker attacks (e.g. separated systems, redundant communication infrastructures, sometimes including own cable networks) or natural and physical impact (e.g. guarded and armored fire/police stations). However (or because of these issues) existing heterogeneous systems are often encapsulated (caused by ICT security standards), which limits the possibilities for information exchange. Our approach to base a complementing ICT infrastructure on lightweight web technologies proved to be appropriate to demonstrate the possibilities of inter-organizational collaboration. Our approach can easily integrate information sources that provide OGC web services and we were experimenting with the emerging (German) standard DIN SPEC 91287:2012-07 on "data interchange between information systems in civil hazard prevention". Our findings also open perspectives for future research related to aspects of controlling the information flow between emergency services, but also between these organizations and the general public. This has been dependent on the physical presence in the control room and now becomes possible for a larger group. A combination of further improvements and the evaluation with a larger group of emergency services over a longer period will bring more results concerning the practical implications of such tools.

\section{Conclusion}

The research we describe above has entailed a 3 year commitment, starting with an empirical study including initial analyses and reflections on existing interorganizational practices, and continued with iterative prototypical implementations and then to practical evaluations in the application field. The overall goal was identifying the value of, and restrictions entailed in, information and expertise sharing in inter-organizational crisis management. This paper followed the methodology of design case study (Wulf et al. 2011). Our first objective was to empirically research collaboration practices in information and expertise sharing in an inter-organizational crisis management setting, where improvisation (as the literature indicates) plays an important role for coping and recovery work; our second objective was to answer the question, how ICT support should be designed to be able to adequately support such practices.

In sum, we have drawn extensively on literatures which demonstrate the problem of inter-organizational cooperation in the domain of crisis management, and specifically on the concept of improvisation. This has been previously addressed as a topic (e.g. Cunha et al. 1999; Mendonça and Wallace 2007; Mendonça 2007; Moorman and Miner 1998; Weick 1993). Nevertheless, we believe that our contribution is to bring the results of a long term qualitative study to bear on the 
specific issues of how, when and in what way improvisation takes place, and what the limitations on its effectiveness might be. In much the same way, we draw on existing understandings of information and expertise sharing (e.g. Ackerman et al. 2013; Harrald 2006; Hiltz and Turoff 1985; Quarantelli 1988; Rankin et al. 2011; Wenger et al. 1989), but do so in order to address the known problem that practitioners suffer "from a lack of options for sharing information among the organizations, but also from a lack of awareness of information about the activities of others" (Ley et al. 2012) and which lead us to research opportunities in the area of "collaborative knowledge bases" which aim to rectify this (Turoff et al. 2004).

Our study, then, translated prior work on organizational behavior - which dealt with the 'that' of improvisation - to a concern with the 'how' of improvisation, geared to the design of technology suitable for such environments. We designed the inter-organizational situation assessment client ISAC and the interorganizational information repository IOIR. Information and expertise sharing approaches using GIS are challenged because "most spatial decisions using geographical information are done by teams, but existing geospatial information technologies [...] have been designed for use by individuals" (Cai 2005). Related approaches such as Convertino et al. (2011) present possibilities for how collaboration technology can reduce the coordination efforts among spatially distributed emergency teams, but their prototypes have not as yet been developed and evaluated with emergency services. Wu et al. (2013) present a "a new collaborative system for teams doing complex geo-spatial planning tasks", but their system focus on one specific geo-collaboration task: "Although the task is well grounded in empirical evidence, geo-collaboration activities can be very diverse" (Wu et al. 2013). Other approaches either focus on mobile collaboration (Monares et al. 2011) or on the integration of citizen involvement (Okolloh 2009; Palen and Liu 2007; Reuter et al. 2013). Our work has combined the different perspectives in improvisation in inter-organizational crisis management as well as information and expertise sharing (Ackerman et al. 2013) and presented a wellfounded empirical study of work practices, a systematic and (we believe) generalizable approach to the design of ICT support, as well as its evaluations with practitioners.

\section{Acknowledgments}

The project 'InfoStrom' was funded by a grant of the German Federal Ministry for Education and Research (No. 13N10712).

\section{References}

Ackerman, M.S., Dachtera, J., Pipek, V. and Wulf, V. (2013). Sharing Knowledge and Expertise: The CSCW View of Knowledge Management. Computer Supported Cooperative Work: The Journal of Collaborative Computing (JCSCW), vol. 22, no. 4, pp. 531-573. 
Ackerman, M.S., Pipek, V. and Wulf, V. (2003). Sharing expertise: Beyond knowledge management. Cambridge MA, USA: MIT-Press.

Bannon, L. and Schmidt, K. (1989). CSCW: Four Characters in Search of a Context. Proceedings of the European Conference on Computer Supported Cooperative Work (ECSCW). Gatwick, London, Great Britain, pp. 358-372.

Bharosa, N., Lee, J. and Janssen, M. (2010). Challenges and obstacles in sharing and coordinating information during multi-agency disaster response: Propositions from field exercises. Information Systems Frontiers, vol. 12, no. 1, pp. 49-65.

Cai, G. (2005). Extending Distributed GIS to Support Geo-Collaborative Crisis Management. Geographic Information Science, vol. 11, no. 1, pp. 4-14.

Chang, Z. and Li, S. (2007). Collaboration enabled GIS Tools for Emergency Operation Centre. In Li, J., Zlatanova, S. and Fabbri, A. (eds): Geomatics Solutions for Disaster Management. Lecture Notes in Geoinformation and Cartography, Berlin Heidelberg, Germany: Springer, pp. 305-320.

Chen, R., Sharman, R., Rao, H.R. and Upadhyaya, S.J. (2008). Coordination in Emergency Response Management. Communications of the ACM, vol. 51, no. 5, pp. 66-73.

Ciborra, C. (1996). Improvisation and Information Technology in Organizations. Proceedings of the International Conference on Information Systems (ICIS). Cleveland, USA, pp. 369-380

Convertino, G., Mentis, H.M., Slavkovic, A., Rosson, M.B. and Carroll, J.M. (2011). Supporting common ground and awareness in emergency management planning. ACM Transactions on Computer-Human Interaction (TOCHI), vol. 18, no. 4, pp. 1-34.

Doherty, G., Karamanis, N. and Luz, S. (2012). Collaboration in Translation: The Impact of Increased Reach on Cross-organisational Work. Computer Supported Cooperative Work (CSCW): The Journal of Collaborative Computing, vol. 21, no. 6, pp. 525-554.

Endsley, M.R. (1995). Toward a theory of situation awareness in dynamic systems. Human Factors, vol. 37, no. 1, pp. 32-64.

Geertz, C. (1973). The Interpretation of Cultures. New York, USA: Basic Books

Harrald, J.R. (2006). Agility and Discipline: Critical Success Factors for Disaster Response. The ANNALS of the American Academy of Political and Social Science, vol. 604, no. 1, pp. 256272.

Heath, C. and Luff, P. (1992). Collaboration and Control: Crisis Management and Multimedia Technology in London Underground Line Control Rooms. Journal of Computer Supported Cooperative Work, vol. 1, no. 1, pp. 24-48.

Hertzum, M., Bansler, J.P., Havn, E.C. and Simonsen, J. (2012). Pilot Implementation : Learning from Field Tests in IS Development. Communications of the AIS, vol. 30, no. 1, pp. 313-328.

Hiltz, S.R. and Turoff, M. (1985). Structuring computer-mediated communication systems to avoid information overload. Communications of the ACM, vol. 28, no. 7, pp. 680-689.

Hiltz, S.R., van de Walle, B. and Turoff, M. (2011). The Domain of Emergency Management Information. In Van De Walle, B., Turoff, M. and Hiltz, S.R. (eds): Information Systems for Emergency Management. New York, USA; London, Great Britain: M.E. Sharpe,, pp. 3-20.

Hobson, S., Anand, R., Yang, J. and Lee, J. (2011). Towards interoperability in municipal government: a study of information sharing practices. In Campos, P., Graham, N., Jorge, J., Nunes, N., Palanque, P. and Winckler, M. (eds): Human-Computer Interaction - INTERACT 2011. Springer, pp. 233-247.

Kendra, J.M. and Wachtendorf, T. (2003). Elements of Resilience After the World Trade Center Disaster: Reconstituting New York City's Emergency Operations Centre. Disasters, vol. 27, no. 1, pp. 37-53.

Kerr, A. (2002). A qualitative study of shift handover practice and function from a sociotechnical perspective. Journal of Advanced Nursing, vol. 37, no. 2, pp. 125-134.

Klosterman, R. (1999). The what if? Collaborative planning support system. Environment and Planning B, vol. 26, pp. 393-408 
Kraut, R., Gergle, D. and Fussell, S. (2002). The use of visual information in shared visual spaces: Informing the development of virtual co-presence. Proceedings of the Conference on Computer Supported Cooperative Work (CSCW). pp. 268-277.

Ley, B., Pipek, V., Reuter, C. and Wiedenhoefer, T. (2012). Supporting Improvisation Work in InterOrganizational Crisis Management. Proceedings of the Conference on Human Factors in Computing Systems (CHI). Austin, USA: ACM Press, pp. 1529-1538.

Li, J. and O'Hara, K. (2009). Understanding Distributed Collaboration in Emergency Animal Disease Response. Proceedings of the Conference of the Australian Computer-Human Interaction Special Interest Group (OZ CHI). Melbourne, Australia: ACM-Press, pp. 65-72.

Liu, S.B. and Palen, L. (2010). The New Cartographers: Crisis Map Mashups and the Emergence of Neogeographic Practice. Cartography and Geographic Information Science, vol. 37, no. 1, pp. 69-90.

Ludwig, T., Reuter, C. and Pipek, V. (2013). What You See Is What I Need: Mobile Reporting Practices in Emergencies. In Bertelsen, O.W., Ciolfi, L., Grasso, A. and Papadopoulos, G.A. (eds): Proceedings of the European Conference on Computer Supported Cooperative Work (ECSCW). Paphos, Cyprus: Springer, pp. 181-206.

Martin, D., O’Neill, J., Randall, D. and Rouncefield, M. (2007). How Can I Help You? Call Centres, Classification Work and Coordination. Computer Supported Cooperative Work (CSCW): The Journal of Collaborative Computing, vol. 16, no. 3, pp. 231-264.

Mendonça, D. (2007). Decision support for improvisation in response to extreme events: Learning from the response to the 2001 World Trade Center attack. Decision Support Systems, vol. 43, no. 3, pp. 952-967.

Mendonça, D. and Wallace, W. (2007). A Cognitive Model of Improvisation in Emergency Management. IEEE Transactions on Systems Man and Cybernetics Part A Systems and Humans, vol. 37, no. 4, pp. 547-561.

Monares, Á., Ochoa, S.F., Pino, J.A., Herskovic, V., Rodriguez-Covili, J. and Neyem, A. (2011). Mobile computing in urban emergency situations: Improving the support to firefighters in the field. Expert Systems with Applications, vol. 38, no. 2, pp. 1255-1267.

Moorman, C. and Miner, A.S. (1998). Organizational improvisation and organizational memory. Academy of Management Review, vol. 23, no. 4, pp. 698-723.

Nielsen, J. (1993). Usability Engineering. San Francisco, USA: Morgan Kaufmann.

Nonaka, I., Toyama, R. and Konno, N. (2000). SECI, Ba and Leadership: a Unified Model of Dynamic Knowledge Creation. Long range planning, vol. 33, pp. 5-34.

Normark, M. and Randall, D. (2005). Local Expertise at an Emergency Call Centre. In Gellersen, H., Schmidt, K., Beaudouin-Lafon, M. and Mackay, W. (eds): Proceedings of the European Conference on Computer Supported Cooperative Work (ECSCW). Paris, France: Springer, pp. 347-366.

Okolloh, O. (2009). Ushahidi, or 'testimony': Web 2.0 tools for crowdsourcing crisis information. Participatory Learning and Action, vol. 59, no. 1, pp. 65-70.

Palen, L. and Liu, S.B. (2007). Citizen communications in crisis: anticipating a future of ICTsupported public participation. Proceedings of the Conference on Human Factors in Computing Systems (CHI). San Jose, USA: ACM Press, pp. 727-736.

Paul, S.A. and Reddy, M.C. (2010). Understanding Together: Sensemaking in Collaborative Information Seeking. Proceedings of the Conference on Computer Supported Cooperative Work (CSCW). ACM, pp. 321-330.

Perry, L.T. (1991). Strategic improvising: How to formulate and implement competitive strategies in concert. Organization Dynamics, vol. 19, no. 4, pp. 51-64.

Pettersson, M., Randall, D. and Helgeson, B.O. (2004). Ambiguities, Awareness and Economy : A Study of Emergency Service Work. Computer Supported Cooperative Work: The Journal of Collaborative Computing (JCSCW), vol. 13, no. 20, pp. 125-154. 
Pina e Cunha, M., Vieira da Cunha, J. and Kamoche, K. (1999). Organizational Improvisation: What, When, How and Why. International Journal of Management Reviews, vol. 1, no. 3, pp. 299-341

Quarantelli, E.L. (1988). Disaster Crisis Management: A summary of research findings. Journal of Management Studies, vol. 25, no. 4, pp. 373-385.

Rabinow, P. and Marcus, G. (2008). Designs for an Anthropology of the Contemporary. Durham, USA: Duke University Press.

Randall, D., Harper, R.H.R. and Rouncefield, M. (2007). Fieldwork for Design: Theory and Practice. London, Great Britain: Springer.

Rankin, A., Dahlbäck, N. and Lundberg, J. (2011). A case study of factor influencing role improvisation in crisis response teams. Cognition, Technology \& Work, vol. 15, no. 1, pp. 79-93.

Reuter, C., Heger, O. and Pipek, V. (2013). Combining Real and Virtual Volunteers through Social Media. In Comes, T., Fiedrich, F., Fortier, S., Geldermann, J. and Müller, T. (eds): Proceedings of the Information Systems for Crisis Response and Management (ISCRAM). Baden-Baden, Germany, pp. 780-790.

Reuter, C., Ludwig, T. and Pipek, V. (2014). Ad Hoc Participation in Situation Assessment: Supporting Mobile Collaboration in Emergencies. ACM Transactions on Computer-Human Interaction (TOCHI) vol. 21, no. 4, ACM.

Reuter, C., Marx, A. and Pipek, V. (2012). Crisis Management 2.0: Towards a Systematization of Social Software Use in Crisis Situations. International Journal of Information Systems for Crisis Response and Management (IJISCRAM), vol. 4, no. 1, pp. 1-16.

Reuter, C., Pipek, V., Wiedenhoefer, T. and Ley, B. (2012). Dealing with terminologies in collaborative systems for crisis management. In Rothkrantz, L., Ristvey, J. and Franco, Z. (eds): Proceedings of the Information Systems for Crisis Response and Management (ISCRAM). Vancouver, Canada, pp. 1-5.

Reuter, C. and Ritzkatis, M. (2013). Unterstützung mobiler Geo-Kollaboration zur Lageeinschätzung von Feuerwehr und Polizei. In Alt, R. and Franczyk, B. (eds): Proceedings of the International Conference on Wirtschaftsinformatik. Leipzig, Germany, pp. 1877-1891.

Schafer, W., Ganoe, C.H. and Carroll, J.M. (2007). Supporting Community Emergency Management Planning through a Geocollaboration Software Architecture. Computer Supported Cooperative Work: The Journal of Collaborative Computing (JCSCW), vol. 16, no. 4-5, pp. 501-537.

Schmidt, C. (2004). The Analysis of Semi-Structured Interviews. In Flick, U., v. Kardorff, E. and Steinke, I. (eds): A Companion to Qualitative Research. London, Great Britain: Sage, pp. 253258.

Schraagen, J.M., Huis in't veld, M. and de Koning, L. (2010). Information Sharing During Crisis Management. Journal of Contingencies and Crisis management, vol. 18, no. 2, pp. 117-127.

Turoff, M., Chumer, M., van de Walle, B. and Yao, X. (2004). The design of a dynamic emergency response management information system (DERMIS). The Journal of Information Technology Theory and Application (JITTA), vol. 5, no. 4, pp. 1-35.

Turoff, M., van de Walle, B. and Hiltz, S.R. (2010). Emergency Response Information Systems. Information Systems for Emergency Management, Armonk, USA: M.E. Sharpe, pp. 369-387.

US Department of Defense (2010). Dictionary of Military and Associated Terms. available at: http:// www.dtic.mil/doctrine/new_pubs/jp1_02.pdf.

Weick, K.E. (1993). The collapse of sensemaking in organizations: The Mann Gulch disaster. Administrative Science Quarterly, vol. 38, no. 4, pp. 628-652.

Weick, K.E. (1996). Drop your tools: An allegory for organizational studies. Administrative Science Quarterly, vol. 41, no. 2, pp. 301-313. 
Wenger, D., Quarantelli, E.L. and Dynes, R.R. (1989). Disaster Analysis: Police and Fire Departments. University of Delaware, Disaster Research Center, available at: http://udspace.udel.edu/handle/19716/1141

Wu, A., Convertino, G., Ganoe, C.H., Carroll, J.M. and Zhang, X.L. (2013). Supporting collaborative sense-making in emergency management through geo-visualization. International Journal of Human-Computer Studies (IJHCS), Elsevier, vol. 71, no. 1, pp. 4-23.

Wulf, V., Rohde, M., Pipek, V. and Stevens, G. (2011). Engaging with Practices: Design Case Studies as a Research Framework in CSCW. Proceedings of the Conference on Computer Supported Cooperative Work (CSCW). Hangzhou, China: ACM-Press, pp. 505-512. 